\title{
How guidelines can fail us
}

\author{
Fiona Godlee editor in chief, The BMJ
}

Should patients be offered $\beta$ blockers if they have ischaemic heart disease and are about to undergo high risk surgery? Guidelines from the European Society of Cardiology say that they should, citing evidence that it prevents perioperative myocardial infarction. Others are unconvinced and say that the recommendation should be revoked. Initially set at class 1 , the strongest level, the recommendation was retained in 2011 even though key randomised trials were discredited. In the most recent update of the guidance, published last month, the recommendation still stands, albeit at class IIb.

How does this stack up against the remaining trial evidence? A meta-analysis published in 2013, which excluded the discredited trials, found that perioperative $\beta$ blockade in patients at risk was harmful, associated with a statistically and clinically significant increase in mortality. And the authors of that meta-analysis, writing this week in The BMJ (2014;349:g5210, doi:10.1136/ bmj.g5210), tell a strange and unsettling story of subsequent events, one that is hard to reconcile with the treasured belief that medicine serves the best interests of patients and the public.

Those of us who thought we had seen an end to guidelines drawn up among vested interests behind closed doors will be disappointed. In Graham Cole and Darrel Francis's account, we hear of a secrecy agreement signed by the guideline authors that is so secret that even its existence must be kept secret. Where is the openness on which science depends? We hear of guidelines being led by the authors of the major trials-in this case the very trials that turned out to have corrupted the evidence base. Where is the scope for critique of researchers who are in positions of power? We hear of what I would consider to be too close a relationship between the society and its journal. Where is the space for dissenting voices?

I will be interested to know whether readers share the authors' clear disquiet about distorted priorities. When the series of randomised trials was discredited and the senior author, Don Poldermans, dismissed from his post, the European Society of Cardiology's statement concluded, "We are saddened by Prof Poldermans' situation." Cole and Francis in contrast saw more to be sad about in the patients who may have died as a result of guidelines that were based on falsified and fictitious data. Using the discredited research group's own formula, they calculated that the number of iatrogenic deaths might have reached 800 000 , with half of those occurring after the research had been discredited. This estimate, with caveats and cautions, was published in the society's journal, the European Heart Journal, but the article was almost immediately removed. A substantially revised version, without the estimate of deaths, is apparently due for publication, but the original article is published as an appendix to the article in The BMJ this week.

Let me quote from it: "Professional failure in clinical research is not uncommon. If readers are not watching carefully, journals are not listening seriously, and guideline writers are not free to act swiftly, future failures may again risk enduring harm with global reach. The aviation profession has led the way in systems to prevent, recognize, study, and learn from professional failures. Clinical medicine is now following the same path. We must develop similar systems for research."

Cite this as: BMJ 2014;349:95448

๑ B BMJ Publishing Group Ltd 2014 